\title{
Assessment of Earthquake Disaster Risk in Gansu Province
}

\author{
Wenkai Chen ${ }^{1}$, Huijuan $\mathrm{Pei}^{2}$, Congwang $\mathrm{Xi}^{1}$, Yanping Sun ${ }^{1}$, Wen $\mathrm{Li}^{1}$ \\ ${ }^{1}$ Lanzhou Institute of Seismology, China Earthquake Administration, Lanzhou 730000, China \\ ${ }^{2}$ Lanzhou Library of Chinese Academy of Sciences, Lanzhou 730000, China
}

\author{
甘肃省地震灾害风险评估 \\ 陈文凯 ${ }^{1}$ 裴惠娟 ${ }^{2}$ 习聪望 ${ }^{1}$ 孙艳萍 ${ }^{1}$ 李雯 ${ }^{1}$ \\ 1 中国地震局兰州地震研究所, 兰州 730000 , 中国 \\ 2 中国科学院兰州文献情报中心, 兰州 730000 , 中国
}

\begin{abstract}
This paper established the earthquake disaster risk assessment index system for Gansu Province firstly, determined weights of index factor, and then calculated the earthquake disaster risk, exposure, vulnerability and disaster prevention and mitigation capacity based on GIS software platform, finally mapped the earthquake disaster risk of Gansu Province. The results show that: (1) In macroscopic view, the occurring frequency of earthquake disasters in Gansu was relatively high. The high risk region of earthquake disaster mainly concentrated in three areas of Liangzhou District of Wuwei - Gulang, Tianshui - Dingxi, Longnan - Gnana and presented high spatial agglomeration. (2) Highest risk, higher risk, medium risk, lower risk and lowest risk areas accounted for $4.65 \%$ (20.3 thousands), $16.67 \%$ ( 72.8 thousands kilometers), $21.13 \%$ (92.3 thousands kilometers) and $26.42 \%$ (115.4 thousands kilometers) of total area, respectively.
\end{abstract}

Keywords: Gansu Province; Earthquake Disaster; Risk Assessment

\section{摘要}

本文建立甘肃省地震灾害风险评估指标体系, 采用层 次分析方法确定指标因子权重, 在 GIS 软件平台下 对甘肃省地震灾害危险性、暴露性、脆弱性和防灾减
灾能力进行计算, 得到了甘肃省地震灾害风险评估 图。研究结果表明: (1)甘肃省地震灾害风险程度整体 较高, 在空间上地震灾害高风险区主要分布在 3 个区 域（武威市凉州区-古浪县、天水-定西、陇南-甘南） 且呈现片状分布, 呈现较高的空间集聚形态; (2)全省 高风险区域面积为 2.03 万 $\mathrm{Km}^{2}$, 占全省面积的百分 比为 $4.65 \%$; 较高风险区域的面积为 7.28 万 $\mathrm{Km}^{2}$, 占全省面积的 $16.67 \%$; 中等和较低风险区域相差不 大, 面积分别为 9.23 万 $\mathrm{Km}^{2}$ 和 11.54 万 $\mathrm{Km}^{2}$, 面积 百分比为 $21.13 \%, 26.42 \%$; 低风险区域面积为 13.60 万 $\mathrm{Km}^{2}$ ，占全省总面积的 $31.14 \%$ 。

关键词：甘肃省；地震灾害；风险评估

\section{1. 引言}

地震灾害是对人类威胁最大的自然灾害之一, 全 球每年有超过 100 万次的地震发生, 这相当于大约每 分钟两次地震 ${ }^{[1]}$ 。据历史资料统计, 甘肃省是我国地 震活动频繁的少数几个省份之一, 地震活动水平位居 我国前列, 历史上发生过多次破坏性地震, 这些地震 导致甘肃省遭受严重的人员伤亡和经济损失 ${ }^{[2]}$ 。甘肃 省主要分布有祁连山地震带、天水地震带、阿尔金地 震带等, 历史上的多次破坏性地震也集中在这些断裂 带上, 如 1920 年海原 8.5 级地震、 1927 年古浪 8.0 级地震、1 1932 年昌马 7.6 级地震、1954 年山丹 7.25 级地震等。近几年甘肃省及周边地震 (2008 年汶川 8.0 级地震、 2013 年怅县漳县 6.6 级地震、 2015 年门 源 6.4 级地震) 发生频率明显提高, 且随着地区经济 的快速发展, 地震灾害对我省社会经济的影响会越来 
Risk Analysis and Crisis Response in Big Data Era (RAC-16)

越大 ${ }^{[2]}$ 。

地震灾害风险是指未来地震损失的不确定性, 通 度, 合理安排各地的工程建设和产业分工, 从防灾减 灾角度确定各地未来最合理的城市发展方向 ${ }^{[3]}$, 从而 最大程度上减轻地震灾害导致的损失。地震灾害风险 研究开展较早,在 20 世纪 50 年代初前苏联戈尔克夫 采用烈度最大值风险评估方法编制了《全苏地震区域 划分图》, 将历史上已发生地震中烈度最大的视为该 区将来地震发生的烈度, 但这样往往把重现期比较长 的大地震作为依据, 从而高估了危险性 ${ }^{[4]}$ 。概率风险 分析方法在地震灾害风险分析中被广泛应用 ${ }^{[5-9]}$ 。我 国地震灾害风险研究目前有许多学者作了非常有意 义的探讨 ${ }^{[9-16]}$, 既有从中国大尺度上研究地震灾害风 险 ${ }^{[3,12,15]}$, 也有从我国部分区域研究地震灾害风险 [13-14]。但是对于地震多发区域如甘肃省地震灾害风险 研究较少, 目前无公开发表的论文。本文通过建立甘 肃省地震灾害风险评估指标体系, 研究未来甘肃省地 震灾害风险, 以期得到我省未来地震灾害损失的空间 分布, 对高风险区域进行针对性的预防, 从而降低地 震灾害对我省人民生命和财产安全的威胁。

\section{2. 数据来源与处理}

综合风险评估的各个指标数据的准确性直接影 响风险评估的结果精度。在本文中基于 ArcGIS 软件 平台采用统一的投影方式 (高斯克吕格) 与坐标系统 (西安 1980) 对各个指标进行了空间化处理。其中 地形数据来源为 Aster DEM 数据 (日本 ASTER 卫 星), 人口数据为甘肃省人口和计划生育委员会提供 的甘肃省乡镇统计数据（统计数据截止日期为 2013 年 12 月), 经济、医疗卫生、财政收入、储蓄数据来 源于 2014 年甘肃省统计年鉴 (数据为 2013 年数据),
过对未来地震风险的研究, 确定区域未来地震灾害高 风险区, 可以有效提高防震减灾投入的局部资金密 耕地、植被覆盖度、地貌类型来源于中科院资源科学 数据中心, 地震烈度数据采用 2015 年中国地震局发 布的第五代地震动峰值加速度区划图。

\section{3. 地震灾害风险评估}

\section{1. 地震灾害风险评估方法}

区域灾害风险评估是对某一区域内出现灾害损 失及其概率大小的评估 (风险是某一事件发生的概率 和其后果的组合), 评估结果是具体的灾情指标损失 值及出现的概率。地震灾害风险评估一般采用的模型 为:

地震灾害风险度=危险性+暴露性+脆弱性+防灾减灾能力（1）

地震灾害危险性主要指未来地震发生的可能性 和发生地震的强度, 一般通过地震部门确定的地震综 合烈度区划图得到; 暴露性是指区域承载体如人口、 经济为主要关注对象, 人口密度越高, 其暴露性指标 越高; 环境脆弱性方面人类活动越强, 植被覆盖度越 低, 其脆弱性越高; 防灾减灾能力与当地经济、人民 生活水平息息相关, 当地经济和人民生活水平越高, 居住的建筑物质量也越高, 其防灾减灾能力越高。

本文根据自然灾害风险评估理论, 从灾害发生的 危险性、承载体的暴露性和脆弱性以及社会的防灾减 灾能力 4 个方面分别选取评估因子, 构建甘肃省地震 灾害风险评估指标体系。评估指标权重的确定采用层 次分析方法 (analytic hierarchy process, AHP), 根据 各个指标的相对重要性, 从因子层开始, 采用两两比 较的方法建立判断矩阵, 采用方根方法求出各指标因 子的权重并归一, 通过一致性检验后得到因子层对准 则层的权重集（如表 1 所示） ${ }^{[17]}$ 。

表 1. 甘肃省地震灾害综合风险评估指标体系

\begin{tabular}{llll}
\hline 目标层 & 准则层 & 指标层 & 因子层 \\
\hline & & 烈度 $(0.179)$ & 烈度 $(0.179)$ \\
& 危险性 & 地形 $(0.112)$ & 坡度 $(0.112)$ \\
$(0.478)$ & 地震环境 $(0.187)$ & 活动断裂 $(0.129)$ \\
& 人口 $(0.182)$ & 人口密度 $(0.182)$ \\
暴露性 & $(0.249)$ & 经济 $(0.067)$ & 单位面积 GDP $(0.067)$ \\
& 人口与耕地 $(0.083)$ & 土地利用中耕地面积 $(0.083)$ \\
& 脆弱性 $(0.144)$ & 生态环境 $(0.061)$ & 植被覆盖度 $(0.061)$ \\
& 险 & 防救能力 $(0.056)$ & 千人拥有卫生技术人员 $(0.056)$ \\
& $(0.129)$ & 自救能力 $(0.029)$ & 人均储蓄存款 $(0.029)$ \\
& 财力支持能力 $(0.044)$ & 人均地方财政收入 $(0.044)$ \\
\end{tabular}


Risk Analysis and Crisis Response in Big Data Era (RAC-16)

根据建立的地震灾害综合风险评估指标体系, 根 据每个指标的特点选取不同的分级标准, 得到甘肃省 地震灾害风险评估的 11 个分级图, 分为 $1-5$ 级。然 后根据模糊数学方法对各指标因子进行空间运算, 得 到甘肃省地震灾害危险性、暴露性、脆弱性和防灾减 灾能力图 (其中防震减灾能力与地震灾害风险成反比 关系), 计算得到的这四个方面的数据, 最后根据地 震灾害风险评估模型得到地震灾害综合风险评估图。

\section{2. 结果与分析}

\section{(1)地震灾害危险性}

根据本文计算得到甘肃省地震灾害中高危险性 区域主要有 4 个 (如图 1 所示), 分别为酒泉市阿克 塞县-肃北县一带、武威市古浪县、天水市一带和陇 南市-舟曲县一带, 其余高危险区零散分布于张掖市 民乐县和白银市周边; 高危险区面积为 4.03 万 $\mathrm{Km}^{2}$, 占全省总面积的 $9.22 \%$ 。较高危险性的区域面积为 4.66 万 $\mathrm{Km}^{2}$, 占全省面积的百分比为 $10.67 \%$ 。较高 危险性区域分布在河西沿祁连山一带和甘东南地区。 较低和低危险区主要分布在庆阳市、平凉市、兰州市、 民勤县、张掖市和酒泉市瓜州县、肃北县 (北面的飞 地), 面积为 24.18 万 $\mathrm{Km}^{2}$, 百分比为 $55.38 \%$ 。

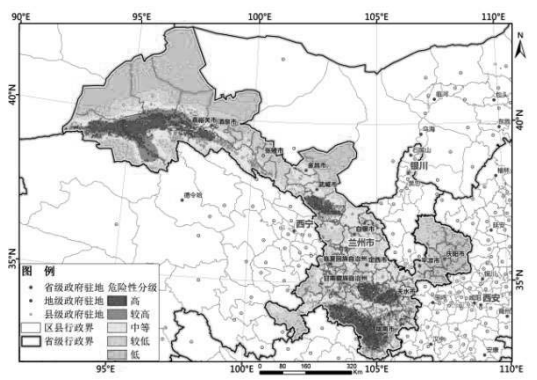

图 1. 甘肃省地震灾害危险性分布图

\section{(2)地震灾害暴露性}

地震灾害暴露性主要由承载体人口和经济决定 的, 通过计算得到甘肃省地震灾害暴露性空间分布特 征 (如图 2 所示)。暴露性较高和高的区域面积为 1.95 万 $\mathrm{Km}^{2}$, 占全省总面积的 $4.47 \%$, 说明甘肃省主要的 人口和经济分布在 $4.47 \%$ 的面积上, 人口和经济高度 积聚, 从图中也可以看出主要分布在市州政府驻地及 其周边地区, 空间上呈现片状分布, 但面积都非常小, 印证了甘肃省经济落后的事实。低和较低暴露性区域 面积为 35.98 万 $\mathrm{Km}^{2}$, 面积百分比为 $82.40 \%$, 主要 分布在河西走廊的戈壁滩和沙漠、甘南州, 这些地区
人烟稀少, 人口密度多在 1 人 $/ \mathrm{Km}^{2}$ 以下。

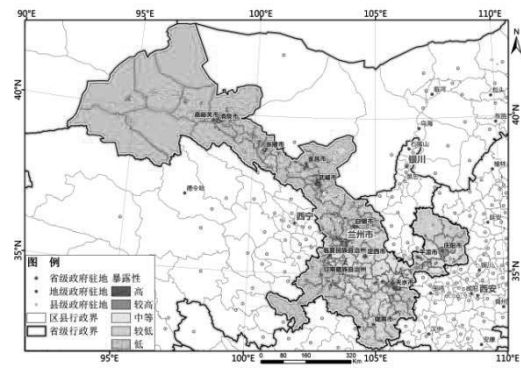

图 2. 甘肃省地震灾害暴露性分布图

\section{(3)地震灾害脆弱性}

地震灾害脆弱性表示主要的承载体人类活动程 度和地理环境承载力。本文以人类活动 (土地利用中 的耕地面积百分比) 和地理环境 (植被覆盖度) 计算 地震灾害脆弱性 (如图 3 所示), 结果表明: 较高和 高脆弱性地区面积为 9.38 万 $\mathrm{Km}^{2}$, 面积百分比为 $21.49 \%$, 主要分布在临夏州、兰州市、天水市、定 西市、平凉市和武威市, 其他地区零星分布。中低脆 弱性区域占绝大多数, 面积为 34.29 万 $\mathrm{Km}^{2}$, 百分比 为 $78.51 \%$, 与人口分布大致相同, 主要分布在人口 稀少的酒泉市、张掖市、武威市民勤县、甘南州等地。

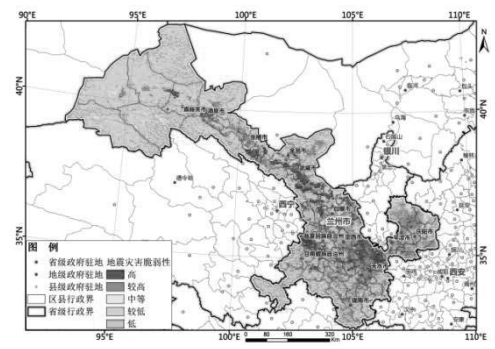

图 3. 甘肃省地震灾害脆弱性分布图

\section{(4)地震灾害防灾减灾能力}

甘肃省经济发展落后, 人均 GDP 几乎每年都是 全国倒数第一, 从本文计算结果 (如图 4 所示), 可 知其防灾减灾能力整体水平较弱, 中低防灾减灾能力 区域面积为 27.25 万 $\mathrm{Km}^{2}$, 面积百分比为 $62.40 \%$ 。 高防灾减灾能力的区域面积为 3.17 万 $\mathrm{Km}^{2}$, 仅占全 省总面积的 $7.28 \%$, 主要分布在兰州市辖区、天水市 辖区和庆阳市, 这个计算结果有些偏大, 因为防灾减 灾能力收集数据最小行政单元为区县, 计算结果的最 小单元也为区县。实际中区县面积中多数地区为农村 
Risk Analysis and Crisis Response in Big Data Era (RAC-16)

地区（经济、医疗卫生和人民收入）低于城镇区域, 高防灾减灾水平的区域实际面积小于本文计算结果。

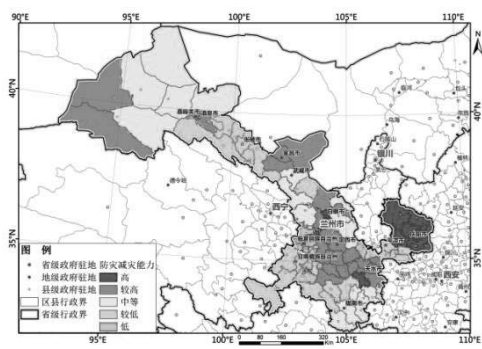

图 4. 甘肃省地震灾害防灾减灾能力分布图

\section{(5)地震灾害综合风险}

根据地震灾害风险评估模型计算, 得到甘肃省地 震灾害风险评估结果如图 5 所示。从图中可知甘肃省 地震灾害高风险区域在空间上主要分布在 3 个区域: 武威市及其邻近区域、天水-定西、陇南-甘南, 其他 地区则零星分布。高风险区域面积为 2.03 万 $\mathrm{Km}^{2}$, 面积百分比为 $4.65 \%$ 。较高风险区域的面积为 7.28 万 $\mathrm{Km}^{2}$, 占全省面积的 $16.67 \%$, 中等和较低风险区 域相差不大，面积分别为 9.23 万 $\mathrm{Km}^{2}$ 和 $11.54 \mathrm{Km}^{2}$, 面积百分比为 $21.13 \%, 26.42 \%$ 。低风险区域面积为 13.60 万 $\mathrm{Km}^{2}$, 占全省总面积的 $31.14 \%$ 。

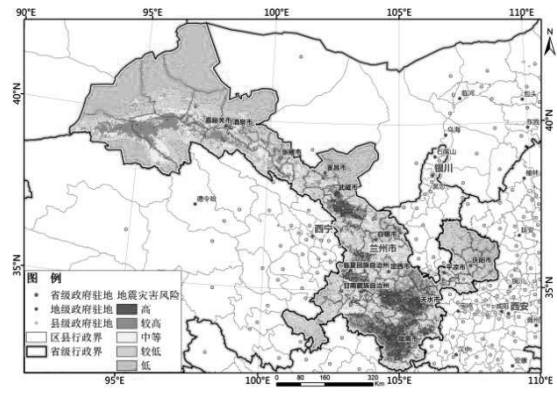

图 5. 甘肃省地震灾害风险图

对地震灾害综合风险评估结果分市州进行统计, 结果如表 2 所示。从表中可以看出甘肃省 14 个市州 中地震灾害高风险的面积百分比最高的是天水市, 面 积百分比为 $28.56 \%$, 其次为陇南市、武威市、临夏 州、定西市、甘南州。14 个市州高风险区域涉及 13 个市州, 庆阳市没有地震灾害高风险和较高风险区域 分布，因此庆阳市地震灾害风险水平较低; 甘肃省较 高地震灾害风险面积比超过 $30 \%$ 的市州有 4 个, 分别
为天水市、平凉市、临夏州、陇南市，其中天水市 $40.12 \%$ 的区域处于较高地震灾害风险程度; 中等地震 灾害风险面积比超过 $30 \%$ 的市州有 6 个, 分别为白银 市、平凉市、临夏州、兰州市、定西市、张掖市，其 中白银市 $47.92 \%$ 的区域处于地震灾害中等风险。风 险评估结果与甘肃省历史地震灾害 ${ }^{[2]}$ 相比有较好的 一致性，一定程度上说明本文评估结果较为可靠。

表 2 甘肃省市州地震灾害综合风险评估等级面积百分比

\begin{tabular}{cccccc}
\hline & \multicolumn{5}{c}{ 地震灾害风险评估等级 } \\
\cline { 2 - 6 } 市州 & 高 & 较高 & 中等 & 较低 & 低(\%) \\
& $(\%)$ & $(\%)$ & $(\%)$ & $(\%)$ & \\
\hline 庆阳市 & 0.00 & 0.00 & 9.22 & 57.04 & 33.74 \\
酒泉市 & 0.19 & 10.88 & 11.88 & 19.09 & 57.96 \\
嘉峪关市 & 0.24 & 8.36 & 16.56 & 49.51 & 25.33 \\
张掖市 & 0.51 & 17.87 & 34.24 & 41.72 & 5.66 \\
白银市 & 1.13 & 18.57 & 47.92 & 29.82 & 2.56 \\
金昌市 & 1.27 & 6.94 & 24.27 & 46.64 & 20.88 \\
平凉市 & 1.56 & 36.54 & 46.63 & 15.11 & 0.16 \\
兰州市 & 1.99 & 17.38 & 37.94 & 38.16 & 4.53 \\
甘南州 & 4.92 & 17.34 & 23.85 & 42.61 & 11.28 \\
定西市 & 7.90 & 27.47 & 36.00 & 27.78 & 0.85 \\
临夏州 & 8.98 & 36.19 & 40.51 & 13.88 & 0.44 \\
武威市 & 9.66 & 16.36 & 12.48 & 16.13 & 45.37 \\
陇南市 & 26.17 & 34.57 & 25.42 & 11.78 & 2.06 \\
天水市 & 28.56 & 40.12 & 18.61 & 11.97 & 0.74 \\
\hline
\end{tabular}

\section{4. 结论}

本文建立了甘肃省地震灾害风险评估指标体系， 采用层次分析方法确定指标因子权重, 在 GIS 软件 平台下对甘肃省地震灾害危险性、暴露性、脆弱性和 防灾减灾能力进行计算, 并在此基础上得到了甘肃省 地震灾害风险评估图。研究结果表明: 甘肃省地震灾 害风险程度整体较高, 甘肃省高风险区域面积为 2.03 万 $\mathrm{Km}^{2}$, 面积百分比为 $4.65 \%$; 较高风险区域的面积 为 7.28 万 $\mathrm{Km}^{2}$, 占全省面积的 $16.67 \%$, 中等和较低 风险区域相差不大, 面积分别为 9.23 万 $\mathrm{Km}^{2}$ 和 11.54 万 $\mathrm{Km}^{2}$, 面积百分比为 $21.13 \%, 26.42 \%$; 低风险区 域面积为 13.60 万 $\mathrm{Km}^{2}$, 占全省总面积的 $31.14 \%$ 。

在空间上主要分布在 3 个区域（武威市凉州区古浪县、天水-定西、陇南-甘南) 且呈现片状分布, 呈现较高的空间集聚形态, 与省内主要活断层分布一 致, 这三个区域分布的活动断裂分别为: 马雅雪山断 裂带、秦岭北缘断裂、东昆仑断裂带。阿尔金断裂带 和疏勒南山断裂区域的地震灾害风险程度较高。按照 
Risk Analysis and Crisis Response in Big Data Era (RAC-16)

市州划分, 地震灾害风险程度最高的市州为天水市、 陇南市、武威市、临夏州、定西市、甘南州; 风险程 度较高的市州为天水市、平凉市、临夏州、陇南市。 这些市州在社会经济规划中应参考 2015 年中国地震 局发布的第五代地震动峰值加速度区划图做好防震 减灾工作, 如根据第五代地震动峰值加速度区划图中 当地烈度值对建筑物进行合适的抗震标准设计, 避免 破坏性地震发生时因建筑物破坏发生人员伤亡和经 济损失。在活动断裂分布的地方因采取避让的方式建 造重大工程项目, 从而减少社会经济损失。

\section{Acknowledgements}

This study was supported by the Fundamental Research Funds in Institute of Earthquake Science China Earthquake Administration (2015IESLZ06) , Science and Technology Support Program of Gansu (1504FKCA065) , West Light Foundation of The Chinese Academy of Sciences.

\section{致谢}

本研究得到了中国地震局地震预测研究所基本科研 业务专项（2015IESLZ06）、甘肃省科技支撑计划 (1504FKCA065) 和中国科学院 “西部之光” 博士 项目的资助。

\section{参考文献}

[1] L Dong, J Shan. A comprehensive review of earthquake-induced building damage detection with remote sensing techniques. ISPRS Journal of Photogrammetry and Remote Sensing. 2013, 84: 85-99

[2] 裴惠娟, 周中红, 孙艳萍等. 甘肃省地震灾害时 空分布特征研究. 自然灾害学报, 2015, 24(3): 67-75

[3] 聂高众, 高建国, 马宗晋等. 中国未来 10-15 年 地震灾害的风险评估. 自然灾害学报, 2002, 11(1): 68-73
[4] 国家地震局.中国地震烈度区划图概论. 北京: 地震出版社, 1996

[5] Yamaguchi A. Bayesian methodology for generic seismic fragility evaluation of components in NPPS. Transactions of the eleventh SMIRT international Conf.1991, M:97-102

[6] Ali M A. Utilizing fuzzy logic for the seismic assessment of Bridge Piers. //Balkema A A. Proc. of the eleventh European Cbnjerence on Earthquake Engineering. Paris, France, Rotterdam-Brooldield , 1998:1-9

[7] Fischer T. An integrated model for earthquake risk assessment of buildings . Engineering Structure, 2002, 24:979-998

[8] Alexandru Carausu and Adrian Vtdpe. Updating fuzzy models for seismic risk assessment Transaction of the sixteen SMIRT international Conf.,2001:1740-1747

[9] 姚清林,黄崇福.地震灾害风险因素和风险评估指 标的模糊算法.自然灾害学报, 2002, 11(2):51-58

[10] 刘伟庆, 徐敬海, 邓民宪. 震害影响因子的多级模 糊综合评判研究. 地震工程与工程振动. 2003,23(2):123-127

[11] 张俊香.新一代自然灾害风险区划原理与方法研 究一以地震灾害为例. 北京: 北京师范大学, 2005

[12] 聂承静, 杨林生, 李海蓉. 中国地震灾害宏观人 口脆弱性评估. 地理科学进展, 2012, 31(3): 375-382

[13] 刘毅, 吴绍洪, 徐中春, 戴尔阜. 自然灾害风险 评估与分级方法论探研一一以山西省地震灾害 风险为例. 地理研究, 2011, 30(2): 195-208.

[14] 苏桂武, 朱林, 马宗晋, 等. 京津唐地区地震灾 害区域宏观脆弱性变化的初步研究: 空间变 化. 地震地质, 2007,29(1):25-33.

[15] 徐伟, 王静爱, 史培军等. 中国城市地震灾害危 险度评价. 自然灾害学报, 2004，13(1): 9-15

[16] 高庆华, 聂高众, 张业成等. 论地震风险. 北京: 气象出版社, 2011: 1-38

[17] Y.Y. Tian, C. Xu, J J. Chen. Regional risk assessment of earthquake-triggered landslides. Journal of Risk Analysis and Crisis Response, 2015, 5(4): 234-245 